Hispania Sacra, LXI

123, enero-junio 2009, 227-256, ISSN: 0018-215-X

\title{
DOS CARAS DE UNA MISMA EXPULSIÓN: EL DESTIERRO DE LOS JESUITAS PORTUGUESES Y LA RECLUSIÓN DE LOS MISIONEROS ALEMANES
}

\author{
POR \\ INMACULADA FERNÁNDEZ ARRILLAGA \\ Mar García AREnAS
}

RESUMEN

La expulsión de los jesuitas de todos los dominios portugueses se inició en 1755 con el paulatino destierro de los religiosos que habitaban las misiones situadas en el Estado amazónico de Gran Pará y Maranhao culminando con la ley general de expulsión que firmó José I el 3 de septiembre de 1759. Un decreto que se iría ejecutando de forma expeditiva en cada uno de los territorios lusos donde vivían miembros de la Compañía de Jesús y desde donde iniciaron su diáspora hacia tierras pontificias. Sin embargo, no todos los jesuitas fueron desterrados a Italia, un considerable número de ellos -entre los que encontramos a todos los que no habían nacido en Portugal-, permanecieron cautivos y confinados en conventos o en casas de campo habilitadas como cárceles y en presidios como el castillo de San Jorge, los fuertes de la Junqueira, Almeida, Pedrouços, San Julián o la cárcel pública de Belem. Cuestiones, todas ellas, de las que trata este trabajo.

PALABRAS CLAVE: Expulsión de los jesuitas, Portugal, presos alemanes, José I, Compañía de Jesús.

\section{TWO SIDES OF THE SAME EXPULSION: THE BANISHMENT OF THE PORTUGUESE JESUITS AND THE RECLUSION FOR GERMANS MISSIONARIES}

\begin{abstract}
The expulsion of the Jesuits in all Portuguese domains began in 1755 with the gradual banishment of the religious who lived missions located in the Amazonian state of Great Para and Maranhao, culminating with the general law of expulsion
\end{abstract}


signed on 3 September of 1759 by Joseph I. A decree done on an expedited basis in each of the territories where lived members of Society of Jesus and from which they launched towards papal lands. However, not all the Jesuits were exiled to Italy, a considerable number of them -among we can find all those who were not born in Portugal-, remained captives and confined in convents or cottages qualified as prisons and in military places as the castle of St. George, the strengths of Junqueira, Almeida, Pedrouços, San Julian or the public prison of Belem. That is what this article is about..

KEY WORDS: Expulsion of the Jesuits, Portugal, German prisoners, Joseph I, Society of Jesus.

Recibido/Received 16-11-2007

Aceptado/Accepted 27-03-2008

Siguiendo la letra del decreto de expulsión de los jesuitas pertenecientes a la corona de Portugal, todo religioso vinculado a la Compañía de Jesús quedaba desterrado de los territorios pertenecientes a José I, sin excepción alguna. La estela de las embarcaciones que, desde las costas lusas, trasladaron a estos religiosos hacia los Estados Pontificios así parecía confirmarlo. Ahora bien, si seguimos las pistas que nos ofrece la valija diplomática austríaca, los escritos que los desterrados redactaron en el exilio y la correspondencia que mantuvieron entre sí, descubriremos que hubo un significativo grupo de jesuitas que sufrieron un destino excepcional: el cautiverio en prisiones lusitanas. Estos son los temas que guían nuestro trabajo: la expulsión de los jesuitas portugueses y la particularidad en el trato con respecto a los considerados súbditos de la emperatriz María Teresa.

\section{Misioneros ALEMANES EN ULTRAMAR}

Hacia 1759, un significativo número de jesuitas extranjeros dependían de la Asistencia lusa de la Compañía de Jesús. La mayoría procedía de la Europa del norte, pero también encontramos otros europeos, si bien es cierto que en menor número. Nos hemos centrado en aquellos jesuitas alemanes ${ }^{1}$ que vivieron muy diversas, y no menos adversas, situaciones: enfrentamientos armados, enfermedades, confinamientos y un largo etcétera. Y pretendemos acercarnos a esos religiosos que, alejados de su país de origen, defendieron una manera de pensar enfrentada al poder político, con un modus operandi considerado poco ortodo-

\footnotetext{
${ }^{1}$ Hemos tomado en consideración los jesuitas pertenecientes a las provincias de la Compañía de Jesús de lengua alemana (Provincia de Austria, Bohemia, Silesia -a partir de 1755-; Alta-Alemania; Alto-Rihn y Bajo-Rihn) a excepción del P. Thoman, que ingresó en Roma, según la relación de Stefan GATZHAMmer: «Antijesuitismo europeu: Relaçoes político-diplomáticas e culturais entre a Baviera e Portugal (1750-1780)», Lusitania Sacra, 5, (1993), pp. 159-250, en p. 215.

Hispania Sacra, LXI

123, enero-junio 2009, 227-256, ISSN: 0018-215-X
} 
xo desde la óptica pombalina, bajo férreas medidas gubernamentales, en medio de una estrecha vigilancia pontificia y en plena selva amazónica. Con estos extranjeros la corona portuguesa mantuvo otro tipo de comportamiento férreo, como si su proceder hubiese sido más trasgresor que el del resto de sus hermanos, y su destino no fueron los Estados Pontificios sino los presidios portugueses de Azeitao $^{2}$, castillo de San Jorge, la cárcel pública de Belem o los fuertes de la Junqueira, Almeida, Pedrouços y San Julián.

Algunos de estos misioneros alemanes habían protagonizado la primera crisis seria que afectó al Brasil colonial, un conflicto que delataba irregularidades en la labor pastoral que debían desarrollar los jesuitas en ultramar y que sirvió de base argumental con la que el entonces Secretario de Estado Sebastián José de Carvalho, futuro conde de Oeiras y después marqués de Pombal, cercenó la actividad y, por consiguiente, la influencia que la Compañía ejercía entre unos indios tan numerosos, dispersos e ignorados como necesarios para el poder. Una tarea evangelizadora e ideológica que, a partir de 1549, desarrolló la Compañía de Jesús desde unas aldeas ${ }^{3}$ que se extendían por el sur del Paraná hasta el alto Amazonas y desde la costa atlántica hasta la meseta de Goiás y en las que los indios eran defendidos de los traficantes de esclavos sin contemplaciones. Además la autoridad del Instituto de san Ignacio se hacía sentir en todas las ciudades importantes brasileñas. En los colegios que regentaban se educaba a la elite y en sus confesionarios se orientaban las conciencias de relevantes personalidades. En las zonas rurales los jesuitas administraban valiosas plantaciones de azúcar y extensos ranchos ganaderos. Además, sus flotillas comerciales, que gozaban de la exención completa de impuestos aduaneros, no dejaban de levantar todo tipo de sospechas ${ }^{4}$.

\footnotetext{
${ }^{2}$ Azeitao era la casa de campo del Duque de Aveiro, que tras ser acusado en el complot del intento de asesinato de José I, fue convertida en cárcel. Tal y como refiere el embajador español en Lisboa en su correspondencia de oficio a Madrid. En Archivo General de Simancas, en adelante, A.G.S, Estado. Leg. 7.263. Conde de Maceda a Ricardo Wall. Lisboa, 18 de septiembre de 1759.

${ }^{3}$ Las tradicionalmente conocidas como Misiones o Reducciones jesuítas, en Brasil se denominaban aldeas. En Dauril ALDEN: The making of a enterprise. The Society of Jesus in portugal, its empire and beyond, 1540-1750, University Press, Stanford, 1996, p. XXIX.

4 «En el Amazonas sus flotillas anuales de canoas llevaban a Belém abundantes cantidades de cacao, clavo, canela y zarzaparrilla, cosechadas a lo largo de los principales afluentes del gran río. Además de las flotillas de pequeñas embarcaciones que unían los centros productivos con la casa central, la Compañía mantenía su propia fragata para facilitar las comunicaciones en el interior de su extensa red.» Leslie Bethell: Historia de América Latina, Vol. 3, Ed. Critica, Barcelona, 1990, p. 317 . Véase también Dauril ALDEN: Royal goverment in colonial Brazil, Berkeley-Los Ángeles, 1968.
} 


\section{EXPONENTES DEL ANTIJESUITISMO LUSO}

Es en este contexto, en el que se desenvolvían una serie de misioneros procedentes de diferentes lugares y, en su mayoría, súbditos de la emperatriz María Teresa de Austria aunque todos ellos pertenecientes a la Asistencia portuguesa de la Compañía de Jesús ${ }^{5}$. Y es, también, en ese momento cuando el marqués de Pombal, respondiendo a su política regalista, envió a Benedicto XIV la declaración de guerra abierta contra los jesuitas expresada en la Relaçao Abreviada ${ }^{6}$ con la que se pretendía frenar el control político y económico de los jesuitas en la zona del Amazonas, ya que, según Pombal:

«los padres se habían estado aprovechando de los indios, los habían incitado contra el Tratado de límites, les propusieron a un indio por Rey, persuadiendo a los infelices de que su influencia en la Corte de Madrid era muy grande, y de que el confesor real [se refiere al P. Rábagol les había asegurado no se ejecutaría nunca el cambio de las reducciones. No caía la responsabilidad de la guerra sobre los inocentes guaraníes, sino sobre los jesuitas» ${ }^{7}$.

En 1769, esta Guerra Guaranítica la convirtió en epopeya Basilio da Gama ${ }^{8}$ en su obra titulada $O$ Uruguay, una pieza literaria que ha sido considerada por Joao Lucio de Azevedo como el Os Lusíadas $^{9}$ de la era pombalina ${ }^{10}$ y que se

\footnotetext{
${ }^{5}$ Aunque aglutinaba a diferentes Provincias, por lo que debería ser considera Asistencia, en la bibliografía lusa aparece siempre referida como Provincia de Portugal, de ahí que también nosotras utilicemos ese término a partir de aquí. Eliminar: Provincia de Portugal (reino, islas atlánticas y enclaves africanos), Provincia de Goa, Provincia de Malabar, Provincia de Japón. Provincia de Japón y las viceprovincias de China y Maranhao.

${ }^{6}$ Relaçao abreviada da república que os religiosos jesuitas das provincias de Portugal e Espanha estabeleceram nos domínios ultramarinos das duas monarchias, e da guerra que nelles têem movido e sustentado contra os exércitos espanhóis e portugueses. Formada pelos registos das secreterias dos dois respectivos principais comissários e plenipotenciários e por otros documentos autênticos. De este folleto se hizo la más vasta campaña propagandística, tanto en Portugal como en el extranjero, tal vez más de veinte mil ejemplares traducidos al francés, italiano y alemán y reeditada en latín formando parte de las pruebas de la Deducción Cronológica y Analítica. En Fortunato AlMEIDA: História da Igreja em Portugal, Coimbra, 1922, p. 287.

${ }^{7}$ Guillermo Kratz: El tratado hispano-portugués de Límites de 1750 y sus consecuencias. Estudios sobre la abolición de la Compañía de Jesús, Roma, 1954, pp. 132-133.

${ }^{8}$ Basilio da Gama (1741-1795), estudió con los jesuitas en Río de Janeiro hasta la expulsión de la Orden. En Italia, ya secularizado, fue protegido por los jesuitas romanos ingresando en la Arcadia romana, donde adoptó el pseudónimo de Termindo Spilio. A su regreso a Lisboa fue encarcelado en 1768 bajo la acusación de filo-jesuitismo y condenado al destierro en Angola. Para reconciliarse con Pombal, envió un poema dedicado a una de sus hijas. Regresó a la Corte lusa y quedo bajo la protección del marqués. Sobre Basilio da Gama véase: Antonio Lopes: Enigma Pombal. Lisboa, 2002, p. 180 y Ch. O’Neill y J. Domínguez: Diccionario Histórico de la Compañía de Jesús, I.H.S.I. - Universidad de Comillas, Roma-Madrid, 2001, Vol. II, p. 1564.

${ }^{9} \mathrm{El}$ mayor poema épico de la expansión portuguesa en ultramar, escrito en 1572 por Luis de Camoes.

10 J. L. Azevedo: O Marquês de Pombal e a sua época. Lisboa, 1990, p. 113.
}

Hispania Sacra, LXI

123, enero-junio 2009, 227-256, ISSN: 0018-215-X 
convirtió en un claro ejemplo de instrumentalización política al servicio de los objetivos regalistas, entre ellos el antijesuitismo ${ }^{11}$ y la «civilización del indio», es decir, su europeización ${ }^{12}$. Así, se expone la inocencia de los indios, «manipulados maquiavélicamente por los jesuitas-, que los mantenían en la esclavitud y en la ignorancia hasta que fueron liberados por el comisario portugués Gomes Freire»13. El poema no sólo justificó, por tanto, la decisión pombalina de expulsar a esos «leños mercenarios» de Portugal, sino que anhelaba su extinción.

Las raíces del antijesuitismo pombalino hay que buscarlas en el Brasil colonial y en los acontecimientos derivados de la firma del Tratado de Límites, un acuerdo entre las coronas de España y Portugal que pretendía poner fin a las disputas territoriales en América y que fue firmado el 16 de enero de $1750^{14}$. En este compromiso, Portugal cedía la colonia de Sacramento a España que, en compensación, entregaba a la corona lusa los territorios situados en la banda oriental del río Uruguay, donde estaban situadas las reducciones jesuitas. Por tanto, se obligaba a estos misioneros a desalojar las famosas misiones y desplazarse a territorio español, quedando los indios que en ellas vivían expuestos a los conocidos abusos de las incursiones de bandeirantes.

Este tratado implicaba, además, una nueva demarcación de fronteras para lo que fueron designadas sendas comisiones; por parte portuguesa Gomes Freire de Andrade se hizo cargo de la parte sur, en el río de la Plata y en la parte norte, Francisco Xavier de Mendoça Furtado, hermano del marqués de Pombal, gobernador de Grao-Pará y Maranhao, ascendido en 1751 al grado de Capitán General. La nueva demarcación fronteriza posibilitó que el marqués pudiera poner en práctica sus ambiciosos planes respecto a América. El objetivo primordial era implantar un nuevo modelo de colonización, incentivando el aumento de la población, pues según el criterio pombalino, de ese factor no sólo dependía el poder y la riqueza de una nación, sino que, al haber una mayor vigilancia de efectivos portugueses se garantizaría la vigilancia fronteriza ${ }^{15}$. En aras de este

${ }^{11}$ El poema recogió todos los delitos imputados por la propaganda pombalina a los jesuitas: maquiavelismo; usurpación del poder temporal; esclavitud indígena; poder mercenario (en clara referencia al cuarto voto y el carácter internacional de la Compañía); instigación de la sublevación indígena; uso de las armas; fomentadores del fanatismo y la discordia...

12 Sobre el proyecto civilizador pombalino, Véase: Geraldo MÁRTIRES CoELHO: «História e representaçao: Mendoça Furtado ou a invençao da Amazónia pombalina», Actas del Congresso O Marquês de Pombal e a sua época, Oeiras-Pombal, 2001, pp. 161-180, en pp. 171-174.

13 Cfr. Pedro A. Vives Azancot: «Nicolás I, rey de Paraguay. La verdad del engaño y viceversa», Historia 16, n 98, (1984), pp. 63-72, en p. 71.

14 Para profundizar sobre el tema véase: G. Kratz: Ob. Cit., 1954.

15 Carta secretesíma de [Pombal] a Gomes Freire de Andrada. Lisboa, 21 de septiembre de 1751. En Carlos Carneiro Mendoça: O marqués de Pombal e o Brasil. Sao Paolo, 1960, p. 188. Citado por Kenneth Maxwell: Marques de Pombal. Paradoxo do Iluminismo. Río de Janeiro, 1996, p. 53. Agradecemos al profesor Juan Rico Giménez la traducción al castellano que ha elaborado de esta obra y que gentilmente nos proporcionó. 
objetivo, el marqués de Pombal recomendó a su hermano, Mendoça Furtado, que los indios fuesen liberados de la tutela religiosa, se incentivase el mestizaje entre indígenas y criollos -para asegurar un crecimiento poblacional continuado ${ }^{16}$, y se estimulase la importación de esclavos africanos a través de una compañía comercial ${ }^{17}$.

Este ideario se plasmó en junio de 1755 cuando se promulgó una triada legislativa que contribuyó a alterar el proceso de explotación de los recursos amazónicos y, en concreto, desmantelaba el edificio misional de la Compañía de Jesús. La ley de 6 de junio restituía a los indios la libertad personal, de bienes y de comercio. Al día siguiente se expedían dos decretos o alvaras con fuerza de ley; el primero, establecía el gobierno y la justicia secular para todas las aldeas regidas por regulares. El segundo, confirmaba los estatutos de la Compañía comercial del Garo-Pará e Maranhao. La oposición de los jesuitas a esta legislación, junto con la sólida creencia en Lisboa que los jesuitas habían instigado la sublevación indígena contra el Tratado de Límites, fueron argumentos suficientes para que el marqués de Pombal determinase que la Compañía de Jesús entorpecía el desarrollo del Estado y, en consecuencia, debía ser eliminada.

Comenzó entonces la ofensiva portuguesa contra los jesuitas. Un instrumento formidable por parte del ministro luso fue la orquestación de una campaña de desprestigio de la Orden por toda Europa, auspiciando la publicación y difusión de una variada literatura antijesuita. La primera obra fue la Relación Abreviada, editada a finales de 1757. En este impreso se vertieron acusaciones generales contra los jesuitas españoles de las reducciones del Paraguay y contra los padres portugueses del Grao-Para y Maranhao y, muy particularmente, contra los misioneros alemanes que trabajaban en las aldeas de la vice-provincia jesuítica.

\section{Deportados de Maranhao (Brasil)}

Gracias a ese ambiente enrarecido, a la pérdida de influencia que la Compañía había sufrido tras la muerte de la reina madre, María Ana de Habsburgo, el

\footnotetext{
${ }^{16}$ El 4 de abril de 1755 se publicó un decreto de ley fomentando el aumento de población brasileña a través de la concesión de privilegios a los naturales del reino, tanto hombres como mujeres, que se casasen con indígenas. Por este alvará, los vasallos portugueses, casados con indias, quedaban libres de cualquier infamia, más aún se harían dignos de la atención real. Además, en las tierras que se establecieran gozarían de preferencia en aquellos cargos para los que estuvieran capacitados; declarando a sus descendientes hábiles y capaces para cualquier empleo, honra o dignidad. También se impuso castigo de destierro a quien denominase cabouclos, o cualquier otro término despectivo a los descendientes de estos matrimonios. En Manuel Lopes de AlmeIDA: Noticias Históricas de Portugal e Brasil (1751-1800, Coimbra, 1964, pp. 55-56.

17 Kenneth MaXwell: Conflicts and conspiracies: Brazil and Portugal 1750-1808, University Press, Cambridge, 1973, p. 15. 
14 de agosto de 1754, y a la promulgación de los decretos o alvaras ya mencionados, fue posible llevar a cabo la primera expulsión de jesuitas del Maranhao. Y es, precisamente, aquí donde se encontraba uno de los misioneros objeto de este trabajo, el P. Roque Hundertpfund. Este jesuita había sido misionero en la aldea Abacaxis en 1747 y, dos años más tarde, la reina M ${ }^{\mathrm{a}}$ Ana de Austria le propuso que quedara a su servicio en palacio, si bien el P. Hundertpfund prefirió volver a su labor misionera en Brasil. Así pues, partió hacia América en 1750 con el encargo de Juan V de fomentar la espiritualidad entre los colonos residentes en las haciendas lusas del Maranhao.

A su llegada a estas misiones, el P. Hundertpfund trabajó como visitador y, a causa de diferentes denuncias levantadas por los colonos al obispo de Pará, Miguel de Bulhoes ${ }^{18}$, fue acusado de conspiración contra la Corona y desterrado el 9 de septiembre de $1755^{19}$. El P. Hundertpfund salió de Maranhao junto a otros jesuitas ${ }^{20}$ y cuando arribó a Portugal, el 19 de noviembre, fue confinado en una residencia alejada de Lisboa. Dadas sus buenas relaciones en la corte austriaca, solicitó a José I licencia para volver a su patria, un permiso que le fue concedido contra la voluntad de Pombal. Este ministro había acusado al misionero en la Relación Abreviada de haber sublevado a los indios del río Negro y haber dejado sin provisiones la región donde debía celebrarse la negociación entre las comisiones demarcadoras, es decir, la española y la portuguesa.

Es en medio de esta tensa situación cuando encontramos al padre Anselmo Eckart, otro de los misioneros alemanes que trataremos en este trabajo, en la

${ }^{18}$ Fray Miguel de Bulhoes y Sousa, natural de Verdemilho (Aveiro), fue fraile dominico. En 1746, fue designado obispo de Malaca, sin llegar a personarse en su diócesis. El 9 de febrero de 1749 llegó a Belem como nuevo obispo de Grao-Pará, cargo que desempeñó hasta 1760, año en que fue destinado al obispado de Leiría, donde murió en 1779. En Arlindo RUBERT: Historia de la Iglesia en Brasil, Editorial Mapfre, Madrid, 1992, p. 309.

19 En agosto de 1755, el obispo de Grao-Para, Miguel de Bulhoes, acusó al P. Roque de urdir una conjura para entregar a los franceses de Cayena el territorio de Pará a cambio de mantener el cautiverio de los indios. Señalando que el P. Roque había utilizado su condición de director espiritual para la conquista de nuevos partidarios. Por lo tanto, cualquier individuo que en los últimos tiempos hubiese llamado al sacerdote germánico para la práctica espiritual, podría ser acusado de crimen de traición. En Tiago Costa Pinto Dos ReIs: «O Governo português e a Companhia de Jesus no quadro da aliança com a Inglaterra: Desarranjos e acomodaçoes (1755-1757)», Lusitania Sacra, 5, (1993), p. 280. En opinión del jesuita portugués José Caeiro, el motivo real de su expulsión se debió a la correspondencia que mantenía con la reina madre, donde podía haber criticado la acción del obispo y del gobernador. Por tanto, a la muerte de la reina madre, pudieron vengarse ordenando su expulsión. En José CAEIRO: História da Expulsao da Companhia de Jesus da Província de Portugal (século XVIII), Vol. I, Lisboa/Sao Paulo, 1991, p. 58.

${ }^{20}$ Los jesuitas deportados fueron, Roque Hundertpfund, Antonio José, y Teodoro da Cruz, gobernador de la misión Caaeta y viceprovincial de Maranhao, que estuvo preso en Almeida, fue trasladado a San Julián en 1762 y falleció en aquel presidio un año antes de que fueran liberados, en julio de 1776, a la edad de 66 años. En Anselmo ECKART: Memórias de um jesuíta prisionero de Pombal, Braga/Sao Paulo,1987, p. 252. 
misión de Trocano ${ }^{21}$. Era ésta una de las reducciones más prósperas de las situadas a orillas del río Madeira y que había gobernado hasta 1755 el P. Antonio José $^{22}$. Cuando este jesuita fue desterrado -junto al P. Hunderfund y en la ya referida primera deportación de jesuitas de la Asistencia de Portugal ${ }^{23}-$, la misión pasó a ser responsabilidad del P. Eckart. Se encontraba Trocano cercana a otras reducciones o aldeas dirigidas también por miembros de la Compañía, como la misión de Abacaxis que, a una distancia «de sólo dos días a través de la selva», dirigía Antonio Meisterburg, otro jesuita alemán.

El marqués de Pombal recelaba que ambos jesuitas, Anselmo Eckart y Antonio Meisterburg, eran «mais engenheiros militares do que jesuítas» $\mathrm{y}$ aseguraba que, armados con ambas piezas de artillería, habían intentado ocupar Trocano con el fin de impedir la fundación de Borba-a-Nova, nombre que recibía la aldea jesuita al reconvertirse en villa secular, y ayudar a los jesuitas españoles que mantenían una contienda en aquella zona fronteriza ${ }^{24}$. Según Caeiro, estos dos jesuitas alemanes sólo pretendían transportar los cañones a Jamari, una misión que dirigía el P. Eckart desde junio de 1755. Lo sospechoso era que las piezas de artillería estaban en la misión el día 1 de enero del año siguiente, justo la fecha que los enviados del gobernador habían fijado para la entrega de la villa a las autoridades civiles y así comenzar con la fundación secular de Borba-aNova. Sostiene Caeiro que los cañones tenían como única función dar mayor solemnidad a algunas fiestas religiosas y que la ciudad fue entregada con toda normalidad y sin ningún tipo de enfrentamiento armado 25 .

Por su parte Eckart, en carta que dirigía al P. Malagrida en $1756^{26}$, le informaba del pelourinho ${ }^{27}$ que habían fijado los portugueses en Trocano y con el que se dejaba constancia la jurisdicción que de entonces en adelante los ministros reales tenían en aquel territorio, pero en ningún momento refiere enfrentamiento armado alguno con los portugueses. Así, resignado pero no sumiso, afirmaba: «era forzoso obedecer cediendo el campo y rebaño a discreción de lobos

21 Situada al sur de Manaus donde en la actualidad se encuentra la ciudad de Borba.

22 El P. José era portugués y figura como perteneciente a la Provincia de Goa. En mayo de 1761 sería llevado a las cárceles de San Julián y liberado en 1777 en A. ECKART: Memorias..., 1987, p. 248; para más información sobre el P. Antonio José véase: J. CAEIRO: Ob. Cit., 1991, pp. 56-57.

23 A. ECKART: Ob. Cit., 1987, p. 252.

${ }^{24}$ Anselmo ECKART: La historia de la persecución de la Compañía de Jesús en Portugal, en M. LuEngo: Colección de Papeles Varios. T. 25 Archivo Histórico de Loyola (A.H.L.), Escritos de jesuitas del s. XVIII, estante 5.

25 J. CAEIRO: Ob. Cit., 1991, p. 303. Véase a este respecto: Constancio EGuía Ruíz: «El espíritu militar de los jesuitas», Revista de Indias, n 16, 1944, pp. 267-319.

26 A. EcKart: Historia de la persecución, en LuEngo, M.: Papeles Varios, T. XXV, p. 196.

27 Columna fijada a la entrada de algunos lugares, donde a veces se exponían las cabezas de los ajusticiados o los reos a la vergüenza. Diccionario Geral Portugués-Espanhol, Vol. I. Ed. Vox, Porto, 1999 , p. 950.

Hispania Sacra, LXI

123, enero-junio 2009, 227-256, ISSN: 0018-215-X 
carniceros». Para mayor complicación de la situación de los jesuitas en Brasil, por aquel tiempo llegaba a América un nuevo decreto del Rey («mejor diré de Carvallo» puntualizaba el P. Eckart), por el que se intimaba el destierro de otros jesuitas, siguiendo las pautas del extrañamiento anterior y dando continuación a una serie de paulatinas y puntuales expulsiones que no finalizaría hasta el destierro generalizado de todos los jesuitas portugueses a principios de septiembre de $1759^{28}$. Entre estos expulsos se encontraba otro misionero alemán, el P. David Fay, misionero de la aldea de San Francisco Javier de Acamá, que fue inculpado explícitamente en la Relación Abreviada de delito de lesa majestad por haberse arrogado el derecho de hacer un tratado con la tribu indígena de los Amanajós en agosto de 1755, a espaldas de las autoridades regias e imponiendo a los indios la condición de quedar bajo el dominio supremo de los misioneros ${ }^{29}$.

En mayo de 1757 se publicaban y entraban en vigor en el Pará y Maranhao las leyes que decretan libertad para los indios y suprimían las misiones, si bien a los padres se les permitía permanecer como párrocos, el gobierno pasaba a manos de funcionarios regios ${ }^{30}$. Siguiendo esa política de «expulsión por goteo» Anselmo Eckart y su compañero Antonio Meisterburg fueron desterrados a finales del mes de noviembre de 1757, junto a otro padre alemán, Lorenzo Kaulen, y deportados a Portugal en una nave de guerra que, a últimos de noviembre, se hizo a la vela con destino a Lisboa, puerto al que arribaron, con al también alemán P. Fay, tras dos meses y medio de navegación, el 12 de febrero de 1758.

\section{PRISIONEROS EN PORTUGAL}

Tres días más tarde atracaban en Lisboa, donde el futuro marqués de Pombal ya había preparado un dispositivo con el fin de recluir a los misioneros en casas de jesuitas y con el mandato explícito de evitar el paso de los padres por las principales ciudades, para evitar posibles reacciones populares. Una vez en tierra, Meisterburg y Kaulen fueron trasladados a la residencia de Lapa (Sernan(elhe) $)^{31}$, perteneciente al Colegio de que la Compañía tenia en Coimbra. En el

${ }^{28}$ El día 24 noviembre de 1757 el P. Eckart data el extrañamiento de otros cinco jesuitas de Brasil: el P. Francisco de Toledo, visitador de la Provincia de Marañón; el P. José de Rocha, rector del Colegio de Marañón; el P. Luis de Oliveira, procurador de las misiones del Pará; el P, Antonio Moreira, maestro de Teología en el mismo Colegio y el P. David Fay perteneciente a la Provincia austriaca, húngaro de nacimiento. Y del que hablaremos más adelante.

${ }_{29}$ Para sustentar esta inculpación en la Relación Abreviada, se añadieron fragmentos de la carta interceptada del P. Fay al procurador vice-provincial, Benito Fonseca, según Caeiro, sacadas de contexto. En J. CAEIRO: Ob. Cit., 1991, p. 303.

30 J. L. AzEvedo: Ob. Cit., p. 134.

31 J.CAEIRO: Ob. Cit., 1999, p. 149. En el relato de Caeiro, en el momento de ejecutarse la sentencia de enero de 1759 se encontraban en dicha residencia desde hacía un año. 
diario que escribió el P. Eckart puede consultarse el recorrido que hicieron hasta su llegada a la residencia de San Fins, perteneciente también al Colegio de Coimbra, el 8 de marzo de $1758^{32}$, donde quedó recluido Eckart, ya que según el relato de Caeiro, el P. Fay fue confinado en la residencia de Roriz, cerca de Oporto $^{33}$. Una vez alojados en sus respectivas estancias, los misioneros alemanes iniciaron un período de confinamiento, pues Pombal había ordenado a los superiores de las residencias que los padres debían quedar bajo vigilancia, advirtiendo la prohibición de alejarse de esa región. Desde este cautiverio los misioneros alemanes asistieron a la ofensiva pombalina contra los jesuitas, que desembocó en la ley de expulsión de 1759.

Durante el tiempo que duró este aislamiento el P. Eckart tuvo noticias de la llegada a Lisboa, el 30 de abril de 1759, de una remesa de jesuitas entre los que se encontraban dos alemanes, el P. Juan Breuer ${ }^{34}$ y, aunque Eckart omitió el nombre del segundo, creemos que se trataba de Matías Piller ${ }^{35}$. Reseñamos este dato porque Breuer y Piller, junto con otros misioneros alemanes, como Rogerio Hundt y Juan Nepumoceno Szluha formaron parte de ese incesante goteo de jesuitas deportados de Brasil antes de la expulsión general el 3 de septiembre de 1759. Cuando se cumplía puntualmente un año del atentado que sufrió José I, firmó Pombal el decreto de expulsión de todos los jesuitas de los dominios de Portugal. Más adelante escribía Eckart:

«... el 15 de septiembre se puso en ejecución este Decreto. Bien entrada la noche pusieron sobre una nave extranjera más de 100 jesuitas (eran todos profesos) de los colegios de Lisboa, Ebora y Coimbra y escoltados de una nave de guerra nacional hasta los confines del Reino, se hicieron a la vela» ${ }^{36}$.

eran los primeros expatriados de Portugal, a los que se les irían uniendo en los Estados Pontificios más de 1.500 expulsos, quedándose cerca de un centenar prisioneros en las cárceles lusas, entre ellos los mencionados misioneros alemanes. Mientras se fue poniendo en marcha los preparativos para el embarque y transporte de la mayoría de los miembros portugueses hacia el exilio, en noviembre de 1759 todos los jesuitas alemanes que se encontraban en Portugal fueron concentrados en distintos presidios. En el fuerte de Al-

32 A. ECKART: Ob. Cit., 1987, pp. 32-34 y 40-43.

33 J. CAEIRO: Ob. Cit. 1999, p. 172. En el relato de Caeiro, en el momento de ejecutarse la sentencia de enero de 1759 se encontraba en dicha residencia.

${ }^{34}$ A. EcKart: Ob. Cit., 1987, p. 73.

35 Según una relación de jesuitas recluidos en Azeitao datada el 6 de octubre de 1759, Breuer y Piller procedían del Colegio de Santo Antao, donde fueron confinados a su llegada a Lisboa. En Antonio FERRAO: «O marqués de Pombal e a expulsao dos jesuitas, 1759», en Boletim da segunda classe da Academia das ciencias de Lisboa, Vol. XVIII, 1932, p. 530.

${ }^{36}$ A. ECKART: Historia de la persecución, en M. LuENGO: Colección, T. 25, p. 248.

Hispania Sacra, LXI

123, enero-junio 2009, 227-256, ISSN: 0018-215-X 
meida ${ }^{37}$ se encarceló a los padres Eckart, Kaulen, Meisterburg y Fay mientras que Breuer, Piller y Szluha ${ }^{38}$ fueron recluidos en la cárcel de Azeitao. Por su parte, el P. Hundt fue encarcelado en San Julián ${ }^{39}$ y el P. Unger ${ }^{40}$ en la cárcel pública de Belén ${ }^{41}$. A estos se les fueron sumando el resto de jesuitas alemanes que fueron llegando a Lisboa en las sucesivas remesas de expulsos procedentes de los dominios ultramarinos y que señalaremos a continuación.

Bárbara de Braganza, reina de España y hermana de José I de Portugal falleció en Madrid en el verano de 1758; al poco tiempo de llegar la noticia a la Corte de Lisboa, el rey portugués enfermaba de gravedad y comenzaban a correr todo tipo de rumores sobre posibles causas. Durante tres meses se mantuvo el suspense, con el agravante de la incertidumbre que hacía temer un trágico desenlace para los jesuitas. Esta inseguridad se vivió en los Colegios de la Compañía con la mayor expectación y el convencimiento de que un desenlace fatal agravaría su delicada situación. Para entonces ya se les había imputado en Oporto el fomento del tumulto que se conocería como «La Revuelta de los Taberneros»y, aunque nunca se encontró prueba fiable en la que basar esas imputaciones, con ese pretexto, el 21 de septiembre de 1757, se expulsó de la Corte a los jesuitas confesores de la familia real y fue emitida una prohibición general de entrada en el palacio real para todos los miembros de la Compañía de Jesús ${ }^{42}$.

No obstante, el germen de la expulsión se estaba gestando en Roma, gracias a la labor desarrollada por el embajador portugués, Francisco de Almada e Mendoça, primo del marqués de Pombal, cuyo mayor logro fue que Benedicto XIV, ante los graves delitos contenidos en la Relación Abreviada, expidiera el breve In Specula Suprema Dignitatis, el 1 de abril de 1758, por el cual otorgaba al cardenal Saldanha plenos poderes para «visitar y reformar las provincias de la Compañía en los mismos reinos y dominios, así como las iglesias, ca-

37 Presidio en la cuidad de Almeida, fronteriza con España. El inicio del conflicto entre ambas coronas peninsulares en 1762, consecuencia de la Guerra de los Siete Años, obligó al gabinete portugués a trasladar a los prisioneros jesuitas a la fortaleza de San Julián.

38 Caeiro, incluye a Juan Nepumoceno en un listado de los padres del Colegio de Santo Antao que fueron trasladados a Azeitao, el 25 de septiembre de 1759. Más adelante podemos reconstruir la suerte de este misionero alemán, que pudo escapar de la prisión, al ser considerado portugués por tenerse en cuenta únicamente su nombre de pila, y embarcado en la segunda remesa de expulsos con destino a Italia, el 6 de octubre de 1759. Cuando las naves que transportaban a los jesuitas llegaron a Génova, el P. Szluha con la ayuda de sus compañeros pudo abandonar el barco y regresar a Alemania. En J. CAEIRO: Ob. Cit, 1999 , pp. 259 y 266-267.

${ }^{39}$ A su llegada a Lisboa, el 14 de noviembre de 1759, fue encarcelado en el fuerte. En Instituto dos Arquivos Nacionais/Torre do Tombo, Ministerio dos Negocios Eclesiasticos e Justicia. En adelante IAN/TT, MNEJ, maço 57, Cx. 46. Relación de los presos jesuitas que se hallan en la fortaleza de San Julián de Barra, 20 de junio de 1768.

40 También aparece en la documentación como P. Hunger.

${ }^{41}$ Cárcel do pateo dos Bichos.

42 S. Gatzhammer: Ob. Cit, p. 170. 
sas profesas y de noviciado, colegios, hospicios, misiones y cualquier otro lugar de cualquier nombre dependiente de la dicha compañía» ${ }^{43}$. Si bien los jesuitas recelaban de los sucesivos envites que protagonizaba el gabinete pombalino, la promulgación del breve no dejó de sorprenderles ya que ni siquiera el General Lorenzo Ricci estaba al tanto de las negociaciones que se llevaban a cabo en Roma y sólo tuvo noticias del breve desde Portugal cuando este fue publicado el 2 de mayo de 1758, cuando Benedicto XIV ya había fallecido. Las consecuencias no se hicieron esperar, durante la primera semana de junio, Saldanha publicó un edicto que prohibía realizar a los jesuitas operaciones mercantiles en los dominios portugueses de Asia, África y América al declararlos culpables de tratos comerciales escandalosos. El edicto culpaba a estos religiosos de pretender usurpar el dominium de Portugal y España en América, la propiedad y libertad de los indios así como el gobierno temporal de estos. En el mismo día en que era publicado el decreto, José Manuel da Cámara, patriarca de Lisboa, separo a los jesuitas de los confesionarios y les impidió predicar en su diócesis ${ }^{44}$, medida que fue inmediatamente seguida por otros obispos ${ }^{45}$.

Sin embargo, la reforma no iba a durar mucho tiempo, el 3 de septiembre de 1758 , José I fue objeto de un atentado en el que resulto levemente herido. Este hecho proporcionó a Pombal el pretexto ideal -el regicidio-, para librarse de su mayor enemigo: la Compañía de Jesús y, de paso, eliminar a los elementos más molestos de la alta nobleza portuguesa que no comulgaban con su concepto de fortalecimiento del Estado ${ }^{46}$. Seguidamente se promulgó un real decreto, el 19 de enero de 1759 , que ordenaba

«la confiscación de todas las propiedades y bienes de la Compañía y el confinamiento de los jesuitas en sus residencias y colegios bajo la acusación de que se habían rebelado contra el rey en Sudamérica y su participación activa en el atentado contra su vida» ${ }^{4}$.

A partir de este decreto, los oficiales con jurisdicción donde se hallaban propiedades de la Compañía recibieron la orden de iniciar un cerco militar que garantizara la realización de inventarios de las propiedades de los jesuitas, al

\footnotetext{
${ }^{43}$ F. Almeida: Ob. Cit., p. 291.

${ }^{44}$ Samuel Miller: Portugal and Rome, 1748-1830. An aspect of the catholic enlightenment. Roma, 1978, p. 62.

${ }^{45}$ Antonio FerRaz: «Aversao de Pombal a os jesuitas. A propósito de um roteiro», Broteria, 122, (1986), pp. 527-539, en p. 530.

46 Jorge Borges DE MACEDo: «Dialéctica da sociedade portuguesa no tempo de Pombal». En Como interpretar a Pombal? Ediçoes Brotéria/Livraria. Lisboa, 1983. P. 20. Los marqueses de Távora y el duque de Aveiro fueron culpados de haber perpetrado el atentado, pero los jesuitas fueron señalados como los autores morales del mismo. En estas circunstancias vuelve a cobrar protagonismo el jesuita italiano Gabriel Malagrida que fue encarcelado junto a otros jesuitas a principios de enero de 1759 .

${ }^{47}$ S. MilleR: Ob. Cit., p. 70.
}

Hispania Sacra, LXI

123, enero-junio 2009, 227-256, ISSN: 0018-215-X 
tiempo que los concentraba en determinados colegios con vistas a la ya madurada orden de expulsión, ejecutada ocho meses después, el 3 de septiembre de 1759. Un extrañamiento que conmovió a toda la Europa católica, marcando un precedente que sería seguido, en la década siguiente, por la mayoría de los monarcas católicos.

\section{LA EXPULSIÓN DE LOS JESUITAS DE PORTUGAL}

El primer Colegio que se movilizó fue el de la ciudad de Elvás. Donde ya habían sido reunidos los padres de Portalegre, Faro, Villaviciosa y un grupo de novicios. La mañana del 1 de septiembre se les comunicó que serían trasladados pero nada se dijo de su lugar de destino. Esa misma tarde fueron escoltados por medio regimiento de soldados al Colegio de Évora, donde se encontraba un considerable número de jóvenes que fueron preventiva y rápidamente separados de casi setenta padres que marcharon del Colegio hacia los embarcaderos del Tajo. Allí llegaron tras un penoso viaje de seis días, a pie y por intrincados caminos. Estos 69 padres subieron a los botes que les estaban esperando y de allí partieron para integrar el convoy que había preparado Pombal, cinco meses antes, para esta misión expatriadora. Por su parte, los 25 jesuitas del Colegio de Santarem comenzaron su exilio el día 12 de septiembre y tardaron tres días y cuatro noches en alcanzar el Tajo, cuando en condiciones normales no se tardaba más de un día. Ese mismo día 12 llegó la orden al Colegio y noviciado de San Antonio de Lisboa, pero tuvieron que pasar tres días de incertidumbre antes de su partida. No se les permitió sacar del Colegio ninguna de sus propiedades $\mathrm{y}$, con lo que llevaban puesto, fueron conducidos al puerto, escoltados por soldados. Una vez embarcados se les mantuvo bajo cubierta hasta alcanzar mar abierta. Cuando subieron al San Nicolás, la nave destinada para su extrañamiento, el número de religiosos a bordo ascendía a ciento treinta y tres, la mayoría profesos.

\section{BREVE ESTANCIA EN LA RADA ALICANTINA}

Las condiciones del viaje fueron duras debido a la escasez de agua y alimentos; los jesuitas se quejaban de que sólo contaban con una cuchara de madera para comer compartida por grupos. Las carencias llegaron a ser tan alarmantes que el propio capitán, vulnerando las órdenes recibidas de no tocar puerto hasta el atraque en Civitavecchia ${ }^{48}$, consideró imprescindible conseguir más provisio-

\footnotetext{
${ }^{48}$ Bajo multa de 400 escudos romanos se prohibía al capitán que facilitara a los jesuitas abandonar la nave antes de llegar al puerto de destino. En J. CAEIRO: Ob. Cit., 1999, p. 245.
} 
nes y, la tarde del 27 de septiembre de 1759, fondeaba el San Nicolás en el puerto español de Alicante ${ }^{49}$. A bordo, el P. Pedro Caetano ${ }^{50}$, superior de los 133 expulsos lusos, escribía al rector del Colegio que tenía la Compañía en esa ciudad:

«Hago esta más por pedir a V.R. su santa bendición y santos sacrificios y de todos esos padres que para exponerle la ocasión y necesidad con que la hago, porque de esto dará el portador a vuestra reverencia más cumplida relación, contentándome yo con decirle que la fuerza de la persecución en Portugal nos arrojó finalmente al mar; tan cargados de oprobios como faltos de lo preciso para una larga navegación. La provisión que se mandó hacer por parte de el ministro de Portugal para 133 sacerdotes que aquí vamos, no sólo es corta, más sórdida e indigna, y peor sin encarecimiento que la que suele hacerse para los esclavos que se transportan de Guinea. Al fin cual la debería hacer un hombre poseído del mayor odio contra nosotros y que de pura rabia nos echa de Portugal. Ruego a V.R. dirija y ayude al portador con su favor y buenos oficios, no sólo para la buena conducta de los encargos, más para la brevedad con que nosotros perderemos tanto viaje. Acabo con ofrecerme y a todos estos desterrados...» ${ }^{51}$

A las 6 de la mañana del día 28, el ministro de Sanidad de Alicante se personaba en el Colegio de los jesuitas para informar al P. José Carbonell, rector alicantino $^{52}$, del atraque del San Nicolás y de los jesuitas portugueses que llevaba a bordo. El P. Carbonell salió para solicitar del gobernador permiso para embarcar y conocer el estado en que se encontraban sus hermanos. El marqués de Alós, gobernador de Alicante 53 , no puso objeción alguna para que subieran también a bordo el resto de jesuitas del Colegio. Pero cuando el rector del Colegio alicantino llegaba a las proximidades del puerto vio cómo desembarcaba un

${ }^{49}$ En el Archivo Municipal de Alicante (A.M.A.), María Jesús Paternida localizó el documento que registra la entrada en puerto de estos religiosos, desde aquí nuestro agradecimiento. A.M.A.: Sanidad. Relaciones de Embarcaciones, 28 de septiembre de 1759: El navío San Nicolás, capitán Josep Orebich, Ragusco de Lisboa. Visto a las 24 horas con 135 pasajeros jesuitas.

${ }^{50}$ Pedro Caetano, natural de Means (obispado de Coimbra), nacido en mayo de 1706. Ingresó en el noviciado de Coimbra a los 16 años, el 18 de octubre de 1723. Profeso el 16 de julio de 1741. En 1759 residía en la casa profesa de Vila Viçosa. Murió en Roma el 27 de junio de 1791. Biblioteca Nacional de Lisboa, en adelante B.N.L., Catálogo de los sujetos que ingresaron en la Compañía de Jesús en la Provincia de Portugal, p. 123. Véase también Patres ac fatres ex antiquae lusitana Societatis Iesu in exilium deportari Maluerunt. Lisboa, 1902, p. V, y J. CAEIRO: Ob. Cit., Vol. III, pp. 106-108.

${ }^{51}$ Archivo Histórico Nacional de Madrid, en adelante A.H.N., Clero jesuitas, Leg. 162: copia de la carta del P. Provincial de Portugal desde el návio al P. Rector del Colegio de la Expectación de Nuestra Señora de Alicante

52 El P. Carbonell, era natural de Gerona, donde había nacido el 27 de enero de 1728. Se ordenó jesuita el 9 de agosto de 1755 y, cuando los jesuitas españoles fueron expulsados por Carlos III, estaba destinado en el Colegio de San Pablo de Valencia. Fue embarcado en Cartagena en la fragata holandesa «La Alida» el 9 de octubre de 1767 con destino a Córcega, en A.G.S. Marina leg 724 y tenemos noticia de que residía en Ferrara durante el último trimestre de 1773, en: A.G.S., D.G.T. Inventario 27, Leg. 1.

53 Enrique Giménez LóPEZ: «Los corregidores de Alicante. Perfil sociológico y político de una élite militar», Revista de Historia Moderna, 6-7, 1986-87, pp. 67-86.

Hispania Sacra, LXI

123, enero-junio 2009, 227-256, ISSN: 0018-215-X 
jesuita y le esperó en tierra. Era el P. Soares ${ }^{54}$, el comisionado que llevaba la carta de su superior para solicitar ayuda de los alicantinos. En la ciudad cargó el P. Soares con gran cantidad de víveres ${ }^{55}$ que ese mismo día llevaron al San Nicolás y, a las 10 de la noche, se hacían a la vela con rumbo a los Estados del Papa.

Dos días más tarde el P. Carbonell escribía desde Alicante al procurador de su Provincia de Aragón para informarle de lo sucedido, le detallaba los alimentos que habían recogido y la alegría del jesuita portugués ya que de

«nueve meses a esta parte a no veían más que desprecios y calumnias por lo que se pasmaban de ver el buen recibimiento que se les hacía... De Portugal nada pueden decir por haberlos sacado de noche acompañados de ministros y soldados, sin darles mas tiempo que para tomar el sombrero y algunos que llevaba dos pares de medias, le quitaron uno y si alguno tenía alguna alhajuela se la quitaron y llego a tanto su insolencia que los reconocieron hasta las faldriqueras y no se les permitió llevar mas que la camisa que tenían puesta. Todo esto les hizo temer algún infausto destino mayormente cuando vieron que uno a uno acompañados de dos soldados les fueron llevando al puerto para el embarco, y al verse unos a otros en el navío fue mucha la consolación de todos, pues decían que juntos no temían ningún trabajo ni aun a la muerte si la juzgaban cercana, lo que aquietó el capitán pidiendo se consolasen, que él era católico y los llevaba a Civitavecchia, puerto inmediato a Roma, y que dejaba afianzada la entrega, muertos o vivos, de los 133, con mil pesos» ${ }^{56}$.

Nada de extraordinario hubieran tenido estos comentarios del P. Carbonell de no ser por las manifestaciones del oficial de la Secretaría de Estado, Juan de Chindurza, en carta al entonces Agente español de Preces, Manuel de Roda, y en la que recogía las mismas consideraciones, a veces literalmente exactas, aunque tamizadas por las interpretaciones que este acontecimiento levantó entre el pueblo alicantino. Decía el oficial:

«Por las cartas de Alicante supe el sábado haber llegado a aquel puerto, después de once días de feliz navegación, el navío que conducía a Civitavecchia 133 jesuitas desde

\footnotetext{
${ }^{54}$ Aunque en la correspondencia de las cartas de Alicante no se especificó el nombre de pila, según el relato de Caeiro era el P. Joao Soares, bautizado el 24 de febrero de 1725 en Arneiros (Obispado de Lamego). Ingresó en la Compañía en Evora el 13 de diciembre de 1739, profesando el cuarto voto el 15 de agosto de 1758. En el momento de la expulsión se hallaba en la casa profesa de San Roque (Lisboa). Murió en Urbania el 12 de marzo de 1793. En Patres ac fratres ex antiquae lusitana Societatis Iesu in exilium deportari Maluerunt. Lisboa, 1902, p. XXII, CAEIRO, J.: Ob. Cit., vol. III, p. 245 y B.N.L., Ob. Cit., p. 108.

55 Según la carta que el rector de Alicante escribió al procurador de la Provincia de Aragón, los portugueses cargaron con: «15 carneros, 300 panes frescos, 80 cántaros de vino y 6 para decir misa, 30 arrobas de uva fresca, 6 de manzanas, 30 docenas de melones y 3 libras de sémola...; un poco de quina, un tabaque de bizcochos, 12 libras de esponjados, 3 arrobas de nieve, 60 libras de chocolate, 2 chocolateras, 6 libras de tabaco y 3 docenas de huevos», A.H.N.: Clero jesuitas, Leg. 162: copia de la carta del P. Carbonell al P. Francisco de Sales.

56 Idem.
} 
Lisboa. El pretexto de esta arribada se dice ser la mala provisión de víveres que llevaba, indignos aún para esclavos de Guinea, pocos y de mala calidad, sin que llevase más que la camisa puesta cada padre. Pudieron facilitar que uno de ellos desembarcase como capellán de la embarcación, y como con el niño del milagro, se derramaron por la ciudad a conmover las piadosas entrañas de sus gentes y recurrir al socorro de aquellos siervos del señor que llevaban en sus semblantes las señas de su inocencia y su caridad, lograron recoger sobre 400 pesos, un cahiz de almendras, 14 sacos de arroz, otros tantos carneros, 20 arrobas de vino, 4 arrobas de chocolate, azúcar de pilón... Dejó a los interesados las ponderaciones de la crueldad y dureza del conde de Oeiras, porque lo hacen con tal vehemencia que arrancan lágrimas, sollozos y ternuras de los corazones más empedernidos ${ }^{57}$.

Resaltaba Chindurza las desconfianzas que surgieron entre algunos alicantinos ante el hecho de que se quejasen los padres de no llevar suficientes víveres alegando que, a nadie habían dicho cuál fue la cantidad exacta de suministro que se cargó en Lisboa, y recalcaban que:

«... con que no enviándolos el rey fidelísimo como embajadores, ni porque vayan a tomar algunas aguas para recobrar su salud, no es extraño que se contentasen con que llevasen carnes saladas, bizcocho y legumbres, que es el mantenimiento común de los navegantes, aun honrados y sin los perendengues de estos pasajeros».

Otros decían que si bien todo el pueblo de Alicante «enternecido abrió sus bolsas», poco o nada había sido lo que los propios jesuitas de la ciudad les habían entregado procedente de su Colegio

«Y en este particular es salada la reflexión de uno de estos picarones medio jansenistas. Decía el tal: la falta más notable era la de camisas en los viajeros y se dice en la carta que una buena señora había mandado hacer 133 para dar una a cada uno, pero que no tuvo efecto porque el navío se hizo luego a la vela. Pues ¿cómo sus benditos hermanos no los socorrieron con las suyas, pudiendo reemplazarse con las que la Bigot ${ }^{58}$ ofrecía hacer? Añadía otro: el capitán veía la gente que había de conducir a su bordo y aun dijo el mismo que había otorgado obligación de entregar a todos los 133 vivos o muertos a Civitavecchia, bajo pena de mil pesos por cada uno que faltase ¿Pues cómo emprendía el viaje sin bastante matalotaje, siendo regular contar con los víveres y aguada para duplicado tiempo por las contingencias del mar? Otro decía: el surtimiento es del cargo y del patrón de la embarcación, no del rey, ni del ministerio y estos tienen probada su intención, en los pocos o ninguno que ha muerto en todo el tiempo de las encerronas»

Podemos pensar, después de leer estos comentarios, que la corta estancia de los jesuitas portugueses en el puerto alicantino no sólo fue muy comentada,

\footnotetext{
57 Biblioteca Nacional de Madrid, sección Manuscritos, en adelante B.N.: Manuscritos, 54-56v: Carta de Chindurza a Roda, diciembre de 1759. Agradecemos a Enrique Giménez López habernos facilitado este documento.

58 Se refiere a la costurera F. Bigot.
}

Hispania Sacra, LXI

123, enero-junio 2009, 227-256, ISSN: 0018-215-X 
sino que dejó ver cómo una parte de la población española ni se extrañaba que estos religiosos fueran desterrados del reino luso, ni censuraban los métodos del marqués de Pombal.

\section{LlegadA DE LOS JESUITAS PORTUGUESES EXPUlsos A LOS EstAdOS PONTIFICIOS}

Pero volvamos al San Nicolás, donde este primer grupo de 133 exiliados portugueses, conseguía atracar en Civitavecchia el 24 de octubre de 1759. Consecuente con su con su política Pombal no había enviado ningún tipo de notificación formal a Roma informando de sus planes, por lo que, de forma expeditiva, se preparó la acogida de estos religiosos en los Estados Pontificios, ordenando Clemente XIII que fueran llevados a casas de diferentes órdenes hasta ver dónde quedaban definitivamente instalados. Una vez en la Ciudad Santa, se les hospedó en Villa Rufinella de Frascatti, dependiente del Colegio Romano. A la ciudad vaticana, había llegado la correspondencia que el P. Carbonell envió desde Alicante a su superior, y que éste remitió al General. El P. Lorenzo Ricci hizo saber al Papa lo acontecido en ese puerto español y el cardenal Torregiani, Secretario de Estado, protestó ante el ministro de Ragusa ${ }^{59}$ quien se lo comentó a Almada, embajador luso en Roma. Pero para entonces éste ministro plenipotenciario ya tenía noticia del desembarco y previniendo las críticas que iba a recibir su país por la utilización que podría darse de los hechos, ordenó al capitán del San Nicolás la elaboración de un exhaustivo informe, sobre las provisiones y material dispuesto en el barco para el pasaje, en el que explicara lo ocurrido y los motivos que le llevaron a desobedecer las órdenes recibidas en Lisboa.

José Orebich, capitán del San Nicolás, redactó su versión de los hechos en la que aseguraba que, en primer lugar, habían llegado a Alicante y, forzados por el mal tiempo, se habían visto obligados a refugiarse en aquel puerto. En segundo lugar que, ni la falta de provisiones era cierta, ya que él había embarcado todos los alimentos necesarios para el viaje, ni tampoco era veraz el desembarco de ningún jesuita en dicha ciudad. Al contrario, el capitán aseguraba que habían sido jesuitas alicantinos los que se acercaron a la nave y que, después de haber recibido un sobre con dinero portugués, habían traído a bordo una serie de alimentos que encargaron los religiosos lusos, pero que no hacían ninguna falta para poder asegurar la alimentación de los pasajeros hasta Civitavecchia. Naturalmente, se trataba de acabar con los comentarios que incriminaban a la Corte lisboeta de crueldad y maltrato hacia los expulsos y Almada publicó y extendió

\footnotetext{
${ }^{59}$ El navío que trasladó a los primeros jesuitas expulsos de Portugal y que atracó en la rada alicantina era de bandera de la república de Ragusa actual Dubrovnick, en la costa dálmata. (Agradecemos estos datos al profesor Enrique Giménez López) y su capitán era Joseph Orebich.
} 
este informe del capitán Orebich por toda Roma ${ }^{60}$ para desmentir y dejar en evidencia a aquellos que creían los comentarios de los jesuitas. El embajador luso llegó a afirmar que los religiosos no eran más que unos represaliados políticos que tergiversaban los hechos lo que evidenciaba la necesidad de su expulsión «ya que la mentira es una de las características que define a esos miserables y pervertidos pasajeros» 61 .

Mientras tanto, en Coimbra, la noche del 30 de septiembre de1759, salían los jesuitas del que hasta entonces había sido su Colegio. Durante los días previos, habían permanecido en esa casa, vigilados por soldados. El 6 de octubre, 122 religiosos alcanzaban los embarcaderos del Tajo y subían a bordo de dos navíos con destino a Génova. Al llegar a este puerto se les prohibió bajar a tierra y el embajador luso tuvo que pagar al capitán responsable del convoy un dinero extra para que condujera a los jesuitas hasta la ensenada de Civitavecchia. Allí atracaron el 4 de enero de 1760 y fueron destinados primero a Roma y, posteriormente, a Castell Gandolfo.

\section{LA EXPULSIÓN DE LOS MISIONEROS PORTUGUESES DE ULTRAMAR}

Meses más tarde, el 7 de junio de 1760, llegaba a las lejanas misiones del Brasil la orden de expulsión y, aunque no vamos a analizar cómo se desarrolló en las muchas Provincias que tenía la Compañía en la Asistencia de Portugal sí veremos -de manera somera- qué ocurrió en Maranhao y Pará, por ser éstos los territorios en los que la mayoría de los jesuitas alemanes desarrollaban su labor misionera. Nada más arribar los barcos procedentes de la metrópoli, el Colegio de los jesuitas de Maranhao fue rodeado de tropa y se destinaron distintos destacamentos hacia las misiones para que recogieran a los padres allí destinados. Por las calles de la ciudad se fueron poniendo copias del decreto de expatriación y los jesuitas fueron declarados traidores al Estado y enemigos del rey. Los 66 misioneros llegaron al lugar de embarque escoltados; una vez a bordo se les instaló en la bodega donde permanecieron durante los dos primeros días. El 14 de julio salieron hacia Pará y, sólo cuando ya estuvieron fuera del ángulo de visión de la costa, les fue permitido subir a cubierta con la advertencia de que no debían hablar con nadie de la tripulación. A los diez días de travesía alcanzaron el puerto de Pará y tan pronto como echaron anclas los barcos fueron rodeados de soldados destinados a elaborar un listado con los datos de los expulsos. Les

${ }^{60}$ Carta do capitam Joseph Orebich Ragusano, a qual contém a noticia do transporte de 133 padres jesuitas de Lisboa a Civitavecchia. Traduzida fielmente do idioma italiano para o portugués. Lisboa, 1759. En los fondos de la Revista Broteria (Lisboa), cota: 2/22-17.

${ }^{61}$ En A. Ferrão: Ob. Cit., p. 444. 
fue requisado el dinero que llevaban y se les registró para asegurarse que no portaban nada de valor; tras estas diligencias desembarcaron en una playa donde la tropa alineada les marcaba el camino hacia el Colegio.

Las órdenes de expatriación llegaron a Pará en fechas similares pero su ejecución fue mucho más estricta que en ningún otro sitio debido, en gran medida, al celo del gobernador y hermano del marqués de Pombal, Francisco Javier Furtado de Mendoça quien, ayudado de las máximas autoridades eclesiásticas, intentaron advertir a los jóvenes novicios de los riesgos del exilio, ofreciéndoles quedarse en los territorios de la Corona portuguesa e ingresar en otra Orden. Una disposición que imitaría la corte española cuando, en 1767, desterrara a los jesuitas españoles $^{62}$. Hacia la medianoche del 4 de septiembre de aquel 1760 , después de un nuevo y severo registro, los 150 misioneros fueron conducidos por la tropa hacia el lugar de embarque. Su viaje hasta Lisboa contó con las penalidades propias de esas travesías; cuando alcanzaron las orillas del Tajo algunos de estos misioneros fueron llevados a las cercanas prisiones de San Julián de Barra, entre ellos el P. Francisco Wolff de la Provincia Bohemia, los padres Ignacio Szentmartonyi y José Keyling de la Provincia de Austria y el P. Martín Schwartz ${ }^{63}$ de la Alemania septentrional; mientras, los demás jesuitas portugueses eran conducidos hacia $\mathrm{Ci}$ vitavecchia, ciudad en la que atracaron el 17 de enero de 1761.

Pero en las misiones de Goa, donde vivía un considerable número de jesuitas que no habían nacido en Portugal, algunos de ellos alemanes, la represión comenzó cuando el Virrey de la India, conde de Ega, llegó a la isla en diciembre de 1758. Se repartieron ejemplares de la Relación Abreviada y se difundió la noticia de que en Lisboa los jesuitas eran ya tratados por el rey como enemigos del Estado. Antes, pues, de que llegara a Goa la orden de expulsión, el Virrey ya había apresado a los jesuitas en su Colegio, manteniéndolos vigilados con tropa. Cuando llegó la orden de destierro 27 jesuitas embarcaron en el navío Concepción, que partió el 20 de diciembre de 1760 y no alcanzarían la desembocadura del Tajo hasta finales de mayo de 1761, los extranjeros fueron encarcelados en San Julián, entre ellos los padres alemanes Przikril, Müller y Thoman $^{64}$. Ya en 1766 y desde la prisión de San Julián, el P. Carlos Przikril, describía aquel viaje de esta manera:

Embarcamos en Goa en 1761, la travesía duró 5 meses y durante este triste y doloroso viaje perdimos a 23 de nuestros hermanos ${ }^{65}$ [...] Llegamos a la desembocadura del

\footnotetext{
62 Inmaculada FernándeZ ArRILlagA: «Los novicios de la Compañía de Jesús: La disyuntiva ante el autoexilio y su estancia en Italia», Hispania Sacra, n 54, (2002), pp. 169-196.

${ }^{6}$ El P. Schwartz también fue acusado explícitamente en la Relación Abreviada de haber instigado a los hombres de la aldea de Guaricu para evitar que sirvieran de remeros a la comisión demarcadora.

${ }^{64}$ A. ECKART: Ob. Cit., 1987, p. 105.

${ }^{65}$ Entre ellos estaban los alemanes los padres Simon Gumb, Juan Pablo Kéller y José Mautner.
} 
Tajo el día de Corpus Cristi y allí permanecimos 3 días a la espera, el cuarto comenzó el desembarco de algunos padres portugueses, de los pasajeros y de las personas que se había ido recogiendo, pero el resto, unos 104 permanecimos en el barco [...] cuando bajamos a tierra nos condujeron a la torre de San Julián [...] nos encerraron en las mismas mazmorras donde meses antes habian estado nuestros hermanos de Maranhao [...] El P. Wolf entre ellos [...] Me gustaría hacer una descripción de mi celda: es un sótano abovedado, una celda profunda, como una tumba. Su localización al lado del mar causa humedades continuas que traen consigo grandes cantidades de molestos reptiles. Las celdas tienen unos ventanucos por los que justo cabe la comida que nos pasan, pero que no permiten que entre en ellas ni luz ni aire. De todo esto podrá deducir lo pestilentes y poco higiénicas que resultan nuestras celdas [...] los guardias que nos custodian nos tienen prohibido hablar con aquellos que nos sirven [...] El primer día que llegué aquí tuve por colchón la tierra húmeda y por almohada mi breviario [...] Dios desea que permanezcamos totalmente muertos para el mundo ${ }^{66}$.

El resto de los jesuitas de Goa, los 40 portugueses que llegaron con los extranjeros a Lisboa, fueron embarcados hacia Italia, con tan mala fortuna que, en la travesía por el Mediterráneo, fueron apresados por piratas berberiscos y llevados a Argelia. Tras numerosas confusiones y gracias a la gestión diplomática del embajador danés -país de procedencia del buque en el que viajaban-, pudieron salir hacia Roma, alcanzando la costa de Civitavecchia el 8 de julio de 1761. En 1764 llegarían los últimos misioneros desterrados de Macao, entre los que se encontraban los religiosos alemanes Graff y Koffler, que quedaron recluidos en San Julián.

\section{Consecuencias de la eXPulsión en Portugal}

El extrañamiento de los jesuitas lusos tuvo serias consecuencias en Portugal, todas ellas orientadas hacia un mismo punto: disminuir el poder político de la Iglesia, deshacer todo posible vínculo o alianza que significara una decisiva influencia del estamento clerical en los asuntos de gobierno y progresar hacia un nuevo concepto de Estado basado en una monarquía férrea, vigilante en lo eclesiástico y en busca de otro tipo de alianzas. Para ello, a partir de la década de 1760 la política de Pombal entraría en lo que Manuel Antunes ha señalado como la segunda fase de la ofensiva pombalina contra la Compañía ${ }^{67}$ : se persiguió a los simpatizantes de los jesuitas, se intentó fortalecer la alianza de las monarquías católicas para conseguir la extinción de Compañía, se reforzó la or-

\footnotetext{
${ }^{66}$ Alfred WELD: The Suppression of the Society of Jesus in the Portuguese Dominions, Londres, 1877. pp. 361-362. También reproducida en Anécdotas do ministerio do Marquez de Pombal e conde de Oeiras, Sebastián José de Carvalho, sobre o reinado de D. José, T. II, Porto, 1852, pp. 155-161.

67 M. Antunes: «O marques de Pombal e os jesuitas», en VV.AA: Como interpretar a Pombal?, Lisboa-Porto, 1983, pp. 125-144, en p. 132.

Hispania Sacra, LXI

123, enero-junio 2009, 227-256, ISSN: 0018-215-X
} 
todoxia religiosa a través de pastorales acordes con la política del Estado, se reformaron los estudios secundarios y universitarios y se intervino con celo sobre todas las órdenes religiosas con el fin de limitar su crecimiento. Para esto último, y entre otras medidas, se estableció una licencia concedida el Estado de carácter preceptivo para los novicios que quisieran ingresar en alguna Orden. El marqués de Pombal no sólo dirigió su control al clero regular, sino que la rama diocesana de la Iglesia también se resintió; Dauril Alden asegura que «durante todo el final del periodo colonial, sus líderes estuvieron constantemente pidiendo subvenciones para establecer seminarios e incrementar el número de sacerdotes en las áreas no urbanas» ${ }^{6}$, unas peticiones a las que la Corona, como norma general, haría oídos sordos. En el encarcelamiento de los jesuitas foráneos no sólo hay que ver inquina hacia ellos por parte del ministro Pombal, sino un trasfondo más importante que afectaba a la integridad territorial del imperio ultramarino, y era el temor a que las informaciones que estos religiosos pudieran tener sobre las colonias portuguesas cayeran en manos de otras potencias ${ }^{69}$. Esta actitud explicaría el cuidado que tomó el Secretario de Estado portugués para que todos los científicos extranjeros contratados para la demarcación fronteriza, en virtud del Tratado de Límites de 1750, fueran estrechamente vigilados por oficiales portugueses. Entre estos científicos se encontraban varios astrónomos jesuitas como Ignacio Szentmartonyi ${ }^{70}$.

Ahora bien, cabe preguntarse cómo afectaron los acontecimientos que culminaron en el destierro de los portugueses a la imagen de la Compañía de Jesús. A nivel interno, el breve de reforma de Benedicto XIV supuso un golpe tan brusco que los superiores jesuitas reaccionaron, en un principio, con auténtica aversión hacia sus cofrades: el vicario general, Antonio Timoni, como máximo responsable de la Orden hasta la elección del General, propuso que: «la provincia de Portugal sea separada del cuerpo de la Compañía como un miembro infectado» 71 . Una vez elegido Lorenzo Ricci como Prepósito General de los jesuitas, se volvió a plantear la idea de desvincular a los jesuitas pertenecientes a los dominios portugueses del resto de los miembros de la Compañía de Jesús en el Memorial que elevó el P. General a Clemente XIII en defensa de la Orden, el 31 de julio de $1758^{72}$. Ricci proponía la creación de una comisión de cardenales que examinase las acusaciones de las que eran objeto los jesuitas portugueses y «en el caso de que fueran culpables de los delitos, no debe extenderse a todo el cuerpo de jesuitas de la provincia de Portugal, y si todos ellos fueran culpables, tampoco debe extenderse a toda la Compañía». Por eso no es de extrañar que

\footnotetext{
${ }^{68}$ L. Bethell (Ed.): Ob. Cit., p. 322.

69 S. GatZhammer: Ob. Cit., p. 219.

70 G.Kratz: Ob. Cit., pp. 137-138.

${ }^{71}$ S. Miller: Ob. Cit., pp. 62-63.

72 Puede verse una copia en Julio BIKER: Colecçao dos négocios de Roma. T.I, Lisboa, 1874, p. 59-6.1.
} 
los jesuitas italianos, cuando llegaron los lusos desterrados desde Lisboa, les recibieran con desconfianza, pretendiendo destacar sus diferencias para desmarcarse de las acusaciones que habían recibido los lusos. Incluso el P. Timoni se opuso a la sugerencia de pedir licencia papal para que los jesuitas portugueses pudiesen recibir estipendios de misas. Ricci siguió apoyando el parecer de Timoni y, sólo tras la muerte de éste, en julio de 1761, cambió su postura al hacerse insostenible el gasto que suponía mantener a los exiliados ${ }^{73}$. Los jesuitas italianos repitieron esta actitud distante con la llegada de los jesuitas extrañados de los dominios de Carlos III $^{74}$, un ademán que no cesó hasta que, en 1773, la extinción de la Compañía hizo tabla rasa en todos, pero que sí dificultó la integración en Italia de los lusos y complicó su subsistencia, agravada ya por la ausencia de cualquier tipo de ayuda económica procedente de su país hasta 178775 .

\section{LOS MISIONEROS PRESOS EN PORTUGAL}

Recordemos que, mientras la mayoría de los jesuitas de nacionalidad portuguesa se hallaban dispersos por los territorios de los Estados Pontificios, otros miembros de la Compañía de Portugal, la mayoría jesuitas foráneos, permanecían recluidos en los presidios lusos ya mencionados. Y desde esas cárceles los jesuitas alemanes comienzan a solicitar ayuda del exterior a través de cartas clandestinas que logran franquean su aislamiento. El jesuita húngaro Szluha se dirigió en 1759 al Duque de Khevenhüler solicitando que interviniera en su favor. Ese mismo año, el P. Eckart hizo lo propio en una misiva dirigida al rector del colegio de Mannheim. Estos primeros gritos de ayuda fueron infructuosos, pero no parece que lo fueron los de otros presos franceses. De hecho, tuvieron un atisbo de esperanza cuando a mediados de 1766, el embajador galo en Lisboa, el caballero Saint Priest, consiguió la liberación efectiva de los tres jesui-

73 Ch. O’Neill y J. Domínguez: Ob. Cit., Vol. IV, p. 3803.

${ }^{74}$ Cuando los jesuitas españoles fueron desterrados por Carlos III y llegaron a Italia, ésta fue una de las actitudes que más llamó su atención, la incomprensión mostrada por los italianos hacia sus hermanos portugueses, una actitud que también sufrirían los españoles durante los primeros años de su exilio. Inmaculada Fernández ArRILlaga: El destierro de los jesuitas castellanos (1767-1815), Junta de Castilla y León, 2004. Especialmente el capítulo: Hábitos y desamparos entre hermanos, pp. 156 y ss.

75 Los jesuitas portugueses carecieron de cualquier ayuda económica por parte del Estado portugués desde su expulsión en 1759, e incluso María I, reina desde 1777, retrasó diez años la orden de otorgar una pensión a los ex-jesuitas, de 80 y 75 escudos para los sacerdotes y legos, respectivamente. Además, en compensación a los gastos invertidos por la Santa Sede durante 27 años en el mantenimiento de los religiosos lusos, el gobierno portugués acordó el pago de 40.000 cruzados a la Cámara Apostólica. En Miguel CorrêA MonTEIRO: Inácio Monteiro (1724-1812). Um jesuita portugués na dispersao. Centro História da Universidade de Lisboa, Lisboa, 2004, pp. 284-285 y 436-440. Hay una relación con los nombres de los religiosos que percibieron esta ayuda en IAN/TT. M.N.E. Livro 770.

Hispania Sacra, LXI

123, enero-junio 2009, 227-256, ISSN: 0018-215-X 
$\operatorname{tas}^{76}$, por encargo de la reina de Francia, María Lesczinska, esposa de Luis XV77. Esta primera salida desencadenó varias cartas de los jesuitas alemanes, como Przikril o Kaulen, solicitando auxilio a sus provincias de origen que posibilitó que los príncipes alemanes y la emperatriz se involucraran diplomáticamente con el gabinete portugués en la liberación de sus súbditos que han sido registradas por Stefan Gatzhamer ${ }^{78}$, de la misma manera que fueron estudiadas por Bad'Ura para el caso de los jesuitas austriacos en la Asistencia española ${ }^{79}$. En diciembre de 1766, el encargado de negocios y secretario de la embajada imperial en Lisboa, Johan Keil ${ }^{80}$, recibió la orden de intervenir a favor de la redención de once jesuitas, en virtud de su condición de vasallos imperiales. Keil, comenzó entonces a ejercer una presión activa sobre Pombal en defensa de los jesuitas alemanes presos. Detrás de esta reivindicación estaba Kaunitz, que no veía ninguna acción jurídica que justificase la continuación del cautiverio de los misioneros. En abril de 1767, el príncipe elector de Colonia, el obispo de Münster, Max Friedich von Königsegg-Rothenfels, intervino personalmente ante José I a favor de sus súbditos Kaulen, Breuer, Müller y Hundt. Como resultado a estas gestiones, el 10 de julio de 1767 fueron libertados un total de 37 jesuitas extranjeros, entre ellos Jacob Graff, Johann Koffler, Jacob Müller y Karl Przikril. El propio embajador español en Lisboa, marqués de Almodóvar, se hizo eco de las preparativos para este rescate en su correspondencia con Grimaldi ${ }^{81}$.

El príncipe elector de Colonia aprovechó la carta a José I, agradeciendo la puesta en libertad del jesuita Müller -a finales de 1768-, para insistir en la exención de Kaulen, Breuer y Hundt, sin conseguir ningún resultado, al igual que la nueva intervención del diplomático imperial Keil, en 1772, en defensa de los restantes jesuitas presos procedentes de territorios austríacos. Las tentativas de intervención del príncipe elector de Baviera, Maximiliano José III, a favor del P. Martin Schwartz, de Amberg, no están registradas. Pese a estas esperanzadoras liberaciones, hubo algunos religiosos germanos que perecieron durante su cautiverio en San Julián, como los jesuitas Fay y Wolff, en enero de 1767, y el P. Hundt, en abril de

76 Jacques Delsart, Louis du Dad y Jean-Baptiste Ranceau. En A. CARAYON: Les prisons du marquis de Pombal, París, 1865.

${ }^{77}$ Anécdotas..., 1852, T. II, pp. 146-147.

78 S. GATZHAMER: Ob. Cit., pp. 224-230.

79 Bohumil BAD'URA: «El caso de algunos exmisioneros jesuitas austriacos: las gestiones diplomáticas para su liberación», en M. TIETZ y D. BRIESEMEISTER (eds): Los jesuitas españoles expulsos: su contribución al saber sobre el mundo hispánico en la Europa del siglo XVIII, Madrid, 2001, pp. 133168.

80 Johann B. Keil [Kail], fue encargado de los negocios imperiales en Lisboa entre 1759 y 1764, y 1766 a 1768. En Luíz TeXeIra SAmpaYo: Estudos Históricos. Biblioteca Diplomática Serie A, Lisboa, 1984. p. 232.

${ }^{81}$ A.H.N. Estado. leg. 4536, Almodóvar a Grimaldi. Lisboa, 16 de junio de 1767. 
1773. Ese verano se promulgó el breve de extinción de la Compañía que, paradójicamente, no significó ningún cambio para los presos. Tan sólo tras la muerte de José I en febrero de 1777 y la inmediata caída en desgracia del que fuera su ministro, Sebastián José Carvalho, marqués de Pombal, les llegó la libertad.

Los jesuitas germanos una vez liberados, regresaron a sus tierras de origen, y sólo quedó en Lisboa el P. Kaulen, por motivos de salud. Allí, libres de expresar sus ideas y conscientes de la propaganda que con su odisea podrían hacer a favor de la Compañía, describieron su prisión en diarios, cartas y obras más o menos extensas en las que año tras año describen su experiencia para mayor gloria de su Orden, para que no fuera olvidado y, sobre todo, con la esperanza de que, en un futuro, se elaborase una historia de la extinta Compañía con los elementos, las opiniones y los sentimientos de sus protagonistas ${ }^{82}$. Para que no quedara únicamente la opinión oficial, para refutarla, y para resarcirse. Fundamentales fueron los testimonios que dejó Anselmo Eckart, quizá el más conocido de los diaristas alemanes de la Provincia de Portugal ${ }^{83}$, pero no lo fueron menos los comentarios de los padres Kaulen ${ }^{84}$, Breuer ${ }^{85}$, Thoman ${ }^{86}$, Graff ${ }^{87}$, Meisterburg ${ }^{88}$, Przikril ${ }^{89}$ o el P. Müller ${ }^{90}$.

\footnotetext{
${ }^{82} \mathrm{M}^{\mathrm{a}}$ Susana CipolLEtTI: «Fruto de la melancolía, restos del naufragio: el Alto Amazonas en los escritos de los jesuitas expulsos» en M. Tietz y D. Briesemeister (eds.): Ob. Cit., pp. 237-264.

${ }^{83}$ Inmaculada FERNÁNDEZ ARRILLAGA: «Deportaçao do Brasil e prisao nos cárceres portugueses de um jesuíta alemao: o P. Anselmo Eckart», Broteria, Lisboa (febrero 2003), pp. 171-187. Eckart también se encargo de la tradución de parte de la obra Prisiones de Junqueira, del marqués de Alorna, que también sufrió la represión de Ministro Pombal, en Ch. O’Neill y J. Domínguez: Ob. Cit., 2001 Vol. 2 , p. 1176.

${ }^{84}$ Relação de algumas causas que succederão aos religiosos da Companhia de Jesus no reyno de Portugal, nas suas prisões, desterros e carceres, em que estiverão por tempo de 18 annos, isto he do anno 1759 athe o anno 1777, no reinado del Rey D. Jose I sendo Primeiro Ministro... Marquez do Pombal [1784]. Memoria praecipuerum successuum vitae jesuitae anonymi, en el Archivo Torre do Tombo, ms. 147. En Ibidem, Vol. 3, pp. 2179-2180.

${ }^{85}$ Annotatio rerum quarumdam quae religiosis Societatis Jesu contingerunt in Brasilia et Lusitania ab anno 1758 ad annum 1777 prout illas vel ipse expertus fui, vel ab iis narrari audivi, qui interfuerunt, fechado en Colonia el 26 de agosto 1777. S. GatzhAMmER: Ob. Cit., 1993, p. 223.

${ }^{86}$ Mauriz Thommans ehemaligen Jesuitens und Missionaris in Asien und Afrika Reise und Lebensbeschreibung. Ausburg 1788. Ibidem, p. 224.

${ }^{87}$ Eckart informó que en abril de 1765 le fue entregada una carta del P. Graff que relataba su expulsión de Macao y la larga travesía desde el puerto asiático de Goa hasta Lisboa. A. ECKART: Ob. Cit, 1987, pp. 147-148. Extrait d'une lettre d'avril de 1767 sur son retour de Macau. S.GATZHAMMER: $O b$. Cit., 1993, p. 223.

${ }^{88}$ Suspiria captivorum Patrum Societatis Jesu in arce S. Juliani ad ostia Tagi, in natali Beatae Mariae Virginis, 1762. Es una elegía, dedicada a la Virgen María, donde narró los sufrimientos de los jesuitas encarcelados en Almeida y San Julián. En A. ECKART: Ob. Cit, 1987, pp. 125-127.

89 Veáse la carta que hemos reproducido anteriormente.

${ }^{90}$ Erlebnisse und leiden: reisebeschreibung von Cöllen am Rhein nacher Goa und von allen was sich mit einigen Persohnen der Gesellschaft Jesu bis zu iherr Rückkehr in Teutschland merkwürdiges zu getragen vom Jahr 1751 bis 1767. S. GATZHAMMER: Ob. Cit., 1993, p. 224.
} 
Pasados los años, el P. Anselmo Eckart, consiguió reunirse con los jesuitas acogidos por Catalina II, en el único lugar donde la Compañía nunca fue extinta: el noviciado de Polock; allí instruyó a los jóvenes que serían el futuro de la Compañía, entre ellos Juan Jean Philip Roothaan, futuro General de la Orden. El P. Eckart falleció, ya nonagenario, en esa casa de la Rusia Blanca, el 29 de julio de 1809 «siendo el último sobreviviente de las cárceles pombalinas»91.

\section{RESEÑA BIOGRÁFICA DE JESUITAS ALEMANES PRESOS}

\section{1.- BREUER, Juan:}

Nació en Colonia el 25 de junio 1718, e ingresó en la Orden el 21 de octubre de 1735. Fue misionero en Brasil entre 1740-1759. En la década de 1750 fue profesor de Matemáticas del Colegio de Salvador (Bahía). En 1759 fue encarcelado en Azeitao, siendo trasladado el 11 de mayo de 1769 para San Julián de Barra. En 1777 fue liberado y murió en Colonia el 13 de agosto de 1789.

\section{2.- ECKART, Anselmo ${ }^{92}$ :}

Nació en Bingem (Maguncia) el 4 de agosto de 1721 e ingresó en la Compañía el 12 de julio de 1740. En el Colegio de Maguncia fue profesor de latín. En 1752 estuvo en la casa profesa de San Ambrosio de Génova. Fue misionero en Maranhao entre 1753 y 1757. Concretamente, en la misión de Trocano vivió desde junio de 1755 hasta enero de 1756, cuando trasfiere la administración a los funcionarios lusos. En el momento de su deportación de Maranhao, Eckart se encontraba en las misiones de la zona del río Caeté. Trasladado a Portugal fue retenido en la Residencia de los jesuitas de Sanfins (en Valença do Miño), donde elaboró un catálogo sobre la biblioteca de esa casa. Tras la promulgación del decreto de la confiscación de bienes a la Compañía, fue trasladado en febrero de 1759 a la residencia de Sao Joao de Longos Valles, desde donde fue trasladado, en marzo de ese mismo año, al Colegio de Braga. En noviembre de 1759 fue encarcelado en el fuerte de Almeida y a partir de 1762 es trasladado a San Julián. Liberado en 1777. Desempeñó el cargo de maestro de novicios y superior en Dünaburg. Murió en el noviciado de Polock el 29 de junio 1809.

91 A. EcKART: Ob. Cit, 1987, p. 8.

92 Guillermo Kratz: Neue Daten zum Leben des P. Anselm von Eckart, AHSI, 7 (1938), pp. $97-$ 104. También: Inmaculada FernándeZ ArRILlaga: Ob. Cit., (2003). 


\section{3.- FAY, David:}

Nació en febrero 1721, en el castillo de los Fay (Hungría). Misionero en la reducción de Caraca y San José del Maranhao en 1753, donde profeso el cuarto voto en 1755. En 1759 fue encarcelado en el Fuerte de Almeida, siendo trasladado en 1762 a San Julián de Barra, donde murió el 12 de enero de 1767.

\section{4.- GRAFF, Jacobo:}

Nació en 1709 en Niederberg (Trier). Ingresó en la Compañía en 1727 en la Provincia del Bajo Reno. Entre 1738-1764, fue misionero en Conchinchina y Sian. En 1764 encarcelado en el fuerte de San Julián, siendo liberado en 1767. Murió en Trier el 28 de febrero de 1773.

\section{5.- GUMB, Simón:}

Nació el 28 de octubre de 1708 en Weinens (Tirol). Después de ser cantero decidió ingresar en el noviciado de la Compañía de la Provincia del RhinSuperior en 1735. Desde 1745 fue misionero en Tomkin y Goa, murió el 17 de marzo de 1761, durante la travesía de Goa a Lisboa.

\section{6.- HUNDERTPFUND, Roque ${ }^{93}$ :}

Nació en Bregenz (Baviera), el 17 de abril de 1709. Ingresó en la Orden el 9 de octubre de 1724 en la Provincia de la Alta Alemania. Fue maestro de Gramática y Humanidades. Salió hacia las misiones brasileñas y hasta enero de 1747 fue párroco de la aldea de los Abacaxis (margen derecho del río Madeira); en 1749 viajó a Portugal reclamado por Mariana de Austria y al volver al Amazonas fue misionero volante. En 1754 es desterrado de Brasil y conducido a la metrópoli, donde, al no recibir destino solicitó volver a su país natal, permiso que le fue concedido en 1755. El 3 de mayo de 1766 se estableció como profesor en Trento. En 1770 era bibliotecario en Friburgo (Suiza). Murió en Bregenz, en enero de 1777.

\section{7.- HUNDT, Rogelio ${ }^{94}$ :}

Nació en Olpe (Prusia), el 21 de noviembre de 1711. Entró en el noviciado el 23 de octubre de 1731 en la Provincia del Bajo Rhin. Misionero volante. De-

\footnotetext{
93 Véase: Hans ZIPF: «P. Rochus Hundertpfund, S.I., aus Bregenz, ein Amazonasmissionar des 18. Jahrhunderts». Monfort, 28 (1976), pp. 109-143.

94 Veasé: Theo HunDT: «P. Rotger Hundt S.I. Ein Olger reist 1742-1743 nach Brasilien. Heimatstimmen aus derm kreis». En Olpe, 146, (1987), pp. 32-44. Auguste LIESE: «P. Rötger Hundt S.I., auch 
tenido en Bahía en 1759, fue encarcelado a llegada a Portugal, el 14 de noviembre de 1759, en San Julián de Barra, donde murió el 6 de abril de 1773.

\section{8.- KAULEN, Lorenzo 95 :}

Nació en Colonia el 4 mayo de 1716. En 1736 estaba matriculado en la Universidad de Colonia. Fue maestro de Artes liberales, de Filosofía y Teología en la Academia de Colonia, antes de su ingreso en la Compañía, el 21 de octubre de 1738 en la Provincia del Bajo Rhin. A partir de 1750 fue misionero en Maranhao, en la aldea de Piraviri, donde profeso el $4^{\circ}$ voto en 1753. En 1757 expulsado de las misiones de Brasil. A su llegada a Lisboa fue recluido en la casa de campo de Sampaio (Coimbra), tras la orden de confiscación de bienes, en enero de 1759, es llevado a la Residencia de Lapa (Coimbra) y posteriormente, es encarcelado en Almeida, y, desde 1762, en San Julián, donde fue liberado en 1777.

\section{9.- KELLE [KELLER], Juan:}

Nació en Tirol y fue misionero en Goa desde 1753. Murió el 4 de abril de 1761, durante la travesía de Goa a Lisboa.

\section{0.- KEYLING, José96:}

Nació en Schemnitz (Eslovaquia). Ingresó en la Compañía en la Provincia de Austria. Misionero en Maranhao y profesor de Teología, entre 1753 y 1759. Fue preso y conducido a San Julián de Barra en 1760. Liberado en 1777.

\section{1.- KOFFLER, Juan ${ }^{97}$ :}

Nació en Praga el 19 de julio de 1711 y entró en el noviciado de la Provincia de Bohemia en 1726. En 1740 llegó a Macao, desde donde fue enviado a las

\footnotetext{
Rogerio Canisio, oder Canisius Germanus genannt». Sauerländisches Familienarchiv, 4 (1905), pp. 89-98 y del mismo autor: «P. Rutgerus Hundt S.I., Heimatblätter. Zeitschrift der Heimatsvereine des Kreises», Olpe, 5 (1927), pp. 90-93, 103-105, 120-122, 139-141.

95 Véase: H. Hosten: «Een slachtoffer van Pombal. Oud-Vlaamsche vertaling van een brief van P. Laurentius Kaulen, S.I. (Fort van Sint-Julian, 12 Diciembre 1766)», Ker en Missie, 16, (1936), pp. 154157.

96 Veasé: S. GATZHAmmer: Slovensky misiosar u Portugalskom väzemí. Dénes BALÁzs: «Adalékok a dél-amerikai magyar utazók munkásságához». Földrajzi múzeimi Tanulmányok, 2, (1986), pp. 21-24 y 9, (1991), pp. 21-42, en p. 39.

97 Véase: Severin LeITNER: «Pater Johannes Koffler S.I. Ein lebensbild». Gemeindebote vintl, 5 , (1993), pp. 29-30
} 
misiones de Cochinchina, donde estudio medicina. Según Eckart, su condición de médico real le salvó de ser deportado tras la persecuciones contra los cristianos. Preso en San Julián en 1764. El 9 de julio de 1767 fue liberado tras la intervención de la emperatriz. Tras su llegada a Viena, se consagró a las misiones de Transilvania. Murió en diciembre de 1780.

\section{2.- MEISTERBURG, Antonio:}

Nació en Bernkastel, el 16 enero 1719. Ingresó en la Compañía en el noviciado del Bajo Rhin en 1737. Fue maestro de humanidades y, desde 1750, misionero en el Maranhao, en dos aldeas del Grao-Para: Aricará y Abacaxis. Expulso del Brasil en 1757. A su llegada a Lisboa fue recluido en la casa de campo de Sampaio (Coimbra), tras la orden de confiscación de bienes, en enero de 1759, es llevado a la Residencia de Lapa (Coimbra) Trasladado al fuerte de Almeida desde 1759 hasta 1762 en que fue encarcelado en el fuerte de San Julián. Liberado en 1777.

\section{3.- MÜLLER, Jacobo:}

Nació el 26 de febrero de 1717, en Colonia. Entró en la Compañía en la Provincia del Bajo Rhin el año 1738. Misionero farmacéutico en el Colegio Nuevo de Goa entre 1752 y 1759. Fue encarcelado en San Julián el 24 de mayo de 1761. El 9 de julio de 1767 embarcado hacia Italia. A su regresó a Colonia, ejerció el oficio de prefecto de salud del colegio de las Tres Coronas.

\section{4.- PILLER, Matías ${ }^{98}$ :}

Nació en Brünn, en 1720. Ingresó en la Compañía en 1738 en la Provincia de Austria. Desde 1752 hasta 1754 es misionero en Brasil. En 1759 encarcelado en Azeitao y fue trasladado a San Julián en 1769. Fue liberado en 1777. El P. Piller destacó como docente en la Universidad de Budapest donde desarrolló las primeras clases prácticas con la relevante colección de minerales que, en 1774, disponía esta Universidad.

\section{5.- PRZIKRIL, Carlos ${ }^{99}$ :}

Nació el 7 de diciembre de 1718, en Praga. Tras su ingreso en la Orden, en 1734, en la Provincia de Bohemia, fue profesor de Gramática y Humanidades,

\footnotetext{
98 Véase: Zsuzsanna BunKE: «Piller Mátyás (1733-1788) és herbáriuma». Botanikai Közlemények, 72 (1985), pp. 185-195.

${ }_{99}$ Miloslav KrÁSA: «First Czech scholar in India», Archiv Orientálni, 36 (1968), pp. 609-624. También: Kamil ZwELEBIL: «A Czech missionary of the $18^{\text {th }}$ Century as author of a Tamil Grammar», Tamil Culture, 5 (1955), pp. 337-340. 
hasta que en 1748 embarcó como misionero con destino a Goa; entre 1752 y 1759 fue profesor de Teología en el Colegio de San Paulo y canciller de la Universidad de Goa. Encarcelado en San Julián el 24 de mayo de 1761. El 9 de julio de 1767 fue liberado por las gestiones emprendida por la emperatriz. A su regreso a su tierra natal, fue nombrado instructor de Tercer Año, en agosto de 1769. Murió el 8 de enero de 1785, en el seminario de Königgrätz.

\section{6.- SCHWARTZ, Martín ${ }^{100:}$}

Nació en Hamburgo en 1721. Ingresó en la Compañía en la Provincia del Alto Rhin en 1735. Misionero en Pará, en la vice-provincia de Maranhao entre 1753 y 1759. Desempeñaba la dirección de la misión de Guaricuru. Encarcelado en San Julián en 1760, de donde salió en marzo de 1777. Murió en Hamburgo en 1788 .

\section{7.- SZENTMARTONYI, Ignacio ${ }^{101}$ :}

Nació en 1718 en Kotim (Croacia) Ingresó en la Compañía en 1735 en la Provincia de Austria. En 1749, Juan V le destinó como matemático para delimitar las fronteras por el Tratado de Madrid de 1750. En 1753 salió de Lisboa, como astrónomo real, con destino a Pará, formando parte de la expedición delimitadora. El 3 de diciembre de 1760 fue encarcelado en San Julián de Barra, un año después fue trasladado a Azeitao. Liberado en 1777. Murió en Croacia, en 1793.

\section{8.- SZLUHA, Juan Nepomuceno ${ }^{102}$ :}

Nació en Gyalu (Hungría) en 1725. Ingresó en la Compañía en la Provincia de Austria en 1738. Entre 1753-1759 fue misionero en Maranhao, donde fue superior de la misión de San Francisco Javier de Acarará. En 1759 fue encarcelado en Azeitao, y logró esquivar la prisión haciéndose pasar por portugués, siendo exiliado hacia Italia ese mismo año. A su llegada a Hungría, llegó a ser capellán de las tropas imperiales y rector del Colegio de Raab. Tras el Breve de extinción, en 1773, se retiró a Oedenburg, después a la abadía de Saint Croix, y finalmente, en Graz, donde murió.

\footnotetext{
100 Véase: Stefan Gatzhammer,: «Die Scchicksale des Oberpfälzer missionars P. Martin Schwartz S.I». Oberpfälzer Heimat 33, (1989), pp. 129-135.

101 Véase: Laszlo BöGOS,: «Brazilia magyar hitküldérei Szentmartonyi Ignác». Vigilia, 56, (1991), pp. 208-298, y Dénes BALÁzs: «Adalékok a dél-amerikai magyar utazók munkásságához», Földrajzi múzeimi Tanulmányok, 2, (1986), pp. 21-24 y 9, (1991), pp. 21-42.

102 L. BögOs: Ob. Cit., (1991), pp. 729-730.
} 


\section{9.- THOMAN, Mauricio:}

Nació en 1722 en Langernagen (Bodensee). Ingresó en la Compañía en la Provincia de Roma en 1750. Médico misionero en Goa y a partir de 1757 en Mozambique, en la misión de Sambesi. Fue encarcelado en San Julián, el 24 de mayo de 1761, de donde salió en marzo de 1777. Se estableció en Botzen, en el Tirol, donde murió el 19 de diciembre de 1805.

\section{0.- UNGER [Hunger], José:}

Nació en Eger, el 24 de marzo de 1717. Ingresó en la Compañía en la Provincia de Bohemia en 1737. En 1748 formó parte de una expedición de misioneros europeos para las misiones guaraníes solicitada por el procurador de la Provincia de Paraguay. El P. Unger se hizo cargo de la dirección de la misión de Santa Rosa; entre 1749 y 1757, fue cura de la reducción de Loreto, hasta que en un ataque de bandeirantes fue apresado y llevado a la isla de las Serpientes. Fue encarcelado en el monasterio benedictino de Montserrate de Río de Janeiro y enviado a Lisboa, donde se le hizo prisionero en la cárcel pública de Belem, siendo liberado en 1777. Una vez en libertad partió hacia Eger, su cuidad natal, donde en 1780 ejercía de predicador y misionero. El P. Kaulen, comenta algunas anécdotas que le sucedieron a José Unger cuando era misionero en la reducción de San Miguel Mirim, en el Paraguay español103.

\section{1.- WOLFF, Francisco:}

Nació en Landeck (Glatz). Ingresó en la Compañía en 1723 en la Provincia de Bohemia. Entre 1738 y 1759 fue misionero en Maranhao. En 1738 fue en dos ocasiones visitador, posteriormente desempeñó el cargo de Socio del Provincial. Profeso en 1741. El 3 de diciembre de 1760 llegó al puerto de Lisboa y fue llevado al fuerte de San Julián, donde falleció el 24 de enero de 1767.

${ }^{103}$ L. KAULEN: Relaçiao..., p. 202. 